AMERCANDA

Arquitectos / Diseñadores AMERCANDA. Pablo Cordua, Bernd Haller, Alberto Dittborn

Colaboradores Gustavo Amoresano, Ximena Capdeville

Producción VISIÓN Comunicaciones

lluminación LIMARI lightning desisn.

Pascal Chautard, Pedro Valenzuela.

Colaboradores Felipe King, Carolina Pérez

Gráfica TLLT. Alejandra Peralta, Pilar Alcaino

Ubicación Estación Mapocho, Santiaso

Mandante Presidencia de la República de Chile

Materialidad En la nave, estructuras de acero zincado, telas

translúcidas; Mesa presidentes: acero cilindrado pintado al horno

Superficie construida $3.500 \mathrm{~m}^{2}$

Año construcción 2001

Fotografía IMA. Claudio Pérez, Rodrigo Gómez
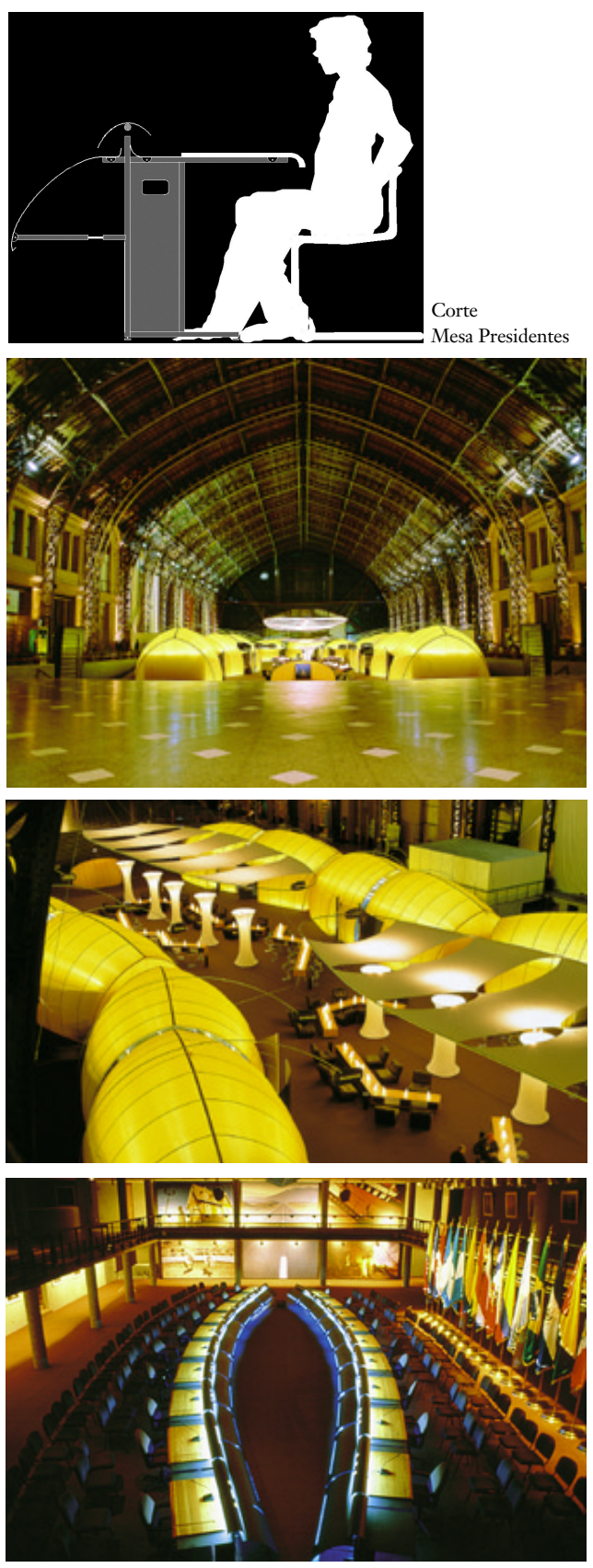

\title{
XV Cumbre Presidencial del Grupo de Río
}

El cliente: La Presidencia de la República fue el anfitrión de la XV Cumbre de Río, integrada por países latinoamericanos y que en esta oportunidad agrupó a 19 de ellos.

El encargo: El tema planteado fue la integración latinoamericana a través de la relaciones que posibilitan internet y las nuevas tecnologías de comunicación ("la modernidad"). Y como toda cumbre, fue una importante oportunidad de encuentro y coordinación de los entes ejecutivos de los gobiernos (más de lo que imaginábamos).

A pesar de que los eventos de esta cumbre no estaban abiertos al público, era de gran importancia para el cliente la imagen que de ella se tuviera a través de la televisión y la prensa.

La propuesta: El montaje está conformado por elementos que expresan la individualidad de cada país como "unidades", y por elementos relacionales que expresan la conexión y comunicación entre ellos: Imagen local-Imagen global: "Desde aquí se mira el mundo": Chile es anfitrión, tiene su identidad y se comunica. Modernidad: entendida como el uso de materiales y técnicas que permiten formas innovadoras para la efectividad de la comunicación contemporánea. Se pretende provocar el contraste con la construcción de la Estación Mapocho mediante conceptos constructivos como liviano y translúcido del adecuado costo para un montaje temporal. Encuentro: el lugar debe provocar las relaciones y los contactos, recibir a los invitados, darles un lugar "de estadía". Imagen mediática: la iluminación es concebida para la filmación tanto como para los usuarios. Se calculan tanto alturas y ángulos para la televisión y los fotógrafos, como la lógica de los recorridos.
Calidez: a pesar del intenso frío, se logra un ambiente cálido mediante la luz, el color y las formas.

\section{Los elementos:}

Nave central: Paisaje del campamento ("aldea global" dijo el cliente en la inauguración), que como las diligencias del oeste, generan una plaza de los encuentros formales o informales, fortuitos o planificados, rápidos o pausados. Cada país es una unidad (oficinas y salas de reuniones) conectada por un sistema de mesones y asientos, altos y bajos.

Sala de Plenarios: Una gran mesa caracterizó la Sala de las Artes, con su imagen de unidades (cada país con un módulo de escritorio) conectadas por medio de un elemento central, continuo y luminoso. La ambientación de la sala consiste en una exposición de fotografías de rostros de latinoamericanos que "supervisan" el trabajo de las delegaciones.

Frontis: La estación fue intervenida respetuosa pero fuertemente. Un elemento gráfico jugó con la fachada. Alterando el color, la luz del interior y exterior, se creó un continuo cambio de percepción mediante la transparencia del soporte.

\section{Pablo Cordua}

Diseñador con estudios de Arquitectura en Santiago y Milán, donde trabajó entre 1989 y 1993. Actualmente se desempeña como profesor de la Escuela de Diseño de la P.U.C

\section{Bernd Haller}

Arquitecto diplomado en Ingeniería, TU Berlin, 1993. Fstudios de pregrado en Architectural Association-Londres y en la Universidad de Delft.

\section{Alberto Dittborn}

Diseñador UC, 1975. Subdirector Museo Interactivo Mirador y Directo de la Escuela de Diseño de la P.U.C.

Desde 1995, Amercanda (Cordua, Dittborn, Haller y Valdés) ha realizado proyectos para diversos montajes de exposiciones, como la XI Bienal de Arquitectura en la Estación Mapocho de Santiago (1997) y el Pabellón de Chile para la Feria Industrial de Hannover (1999).

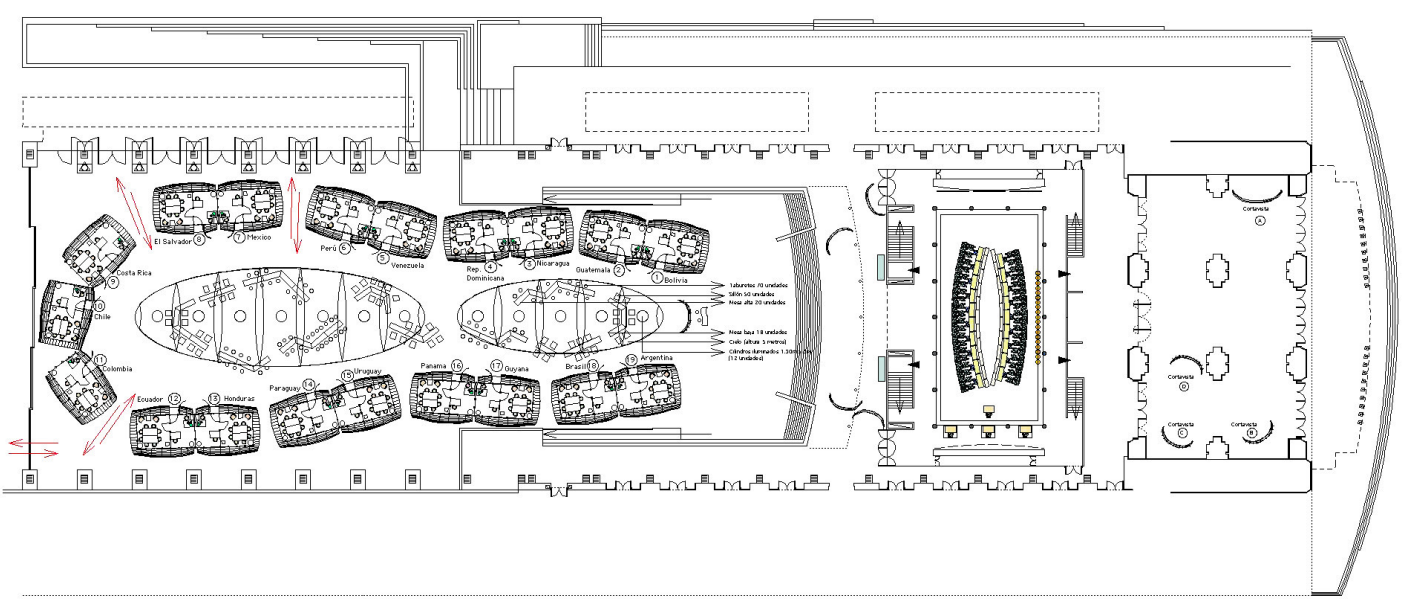

